This is an Accepted Manuscript of an article published by Home Health Care Services Quarterly on 20/4/19, available online: https://www.tandfonline.com/doi/full/10.1080/01621424.2019.1604458

To cite this article:

Debra Palesy \& Samantha Jakimowicz (2019) Health literacy training for Australian home care workers: Enablers and barriers, Home Health Care Services Quarterly, 38:2, 80-95,

DOI: $10.1080 / 01621424.2019 .1604458$

\title{
Health Literacy Training for Australian Home Care Workers: Enablers and Barriers
}

\section{Debra Palesy (corresponding author)}

RN, B Nursing, Grad Dip Ed, MEd, PhD

Lecturer, Faculty of Health

University of Technology Sydney

PO Box 123 Broadway NSW 2007

(M) +61418921051

Debra.Palesy@uts.edu.au

\section{Samantha Jakimowicz}

$\mathrm{RN}, \mathrm{BN}($ Hons1), BCHC, $\mathrm{PhD}$

Lecturer, Faculty of Health

University of Technology Sydney

PO Box 123 Broadway NSW 2007

Samantha.Jakimowicz@uts.edu.au

Correspondence concerning this article should be addressed to Debra Palesy (first author listed above).

This paper has not been submitted to any other journal for review. The authors declare no conflict of interest. This research did not receive any specific grant from funding agencies in the public, commercial, or not-forprofit sectors. 
Health Literacy Training for Australian Home Care Workers: Enablers and Barriers

\begin{abstract}
The rapidly expanding Australian home care workforce represents an untapped resource for improving health literacy (HL) and health outcomes of their clients. Nine home care workers (HCWs) were interviewed for this study to gain data around their experiences of providing HL support to their clients, key HL needs and priorities, and training that would best these needs. Findings indicate that HCWs are providing HL support, and identify a number of enablers and barriers to providing this support. Core inclusions for a HL training checklist are suggested. Implications for future research are considered.
\end{abstract}

\title{
Key words
}

Health literacy; home care worker; care recipient; client; health care; education; training 


\section{Introduction and background}

Health Literacy (HL) generally refers to the ability of a person to access, understand, appraise and apply information to make decisions and take action to manage their health and health care (Nutbeam, 2008). Consistent with other developed countries, approximately $60 \%$ of adult Australians have low levels of HL (Australian Commission on Safety and Quality in Health Care [ACSQHC], 2014), with the elderly and people with cognitive impairment at particularly high risk (Berkman, 2011). Clear links have been established between low HL and poor health outcomes. For example, people with low HL are less likely to access primary or preventative health care services, are more likely to use emergency services and/or be hospitalized, and are more likely to experience adverse health outcomes such as selfmedication errors (ACSQHC, 2014; Berkman, 2011). These factors adversely affect quality of life, morbidity and mortality (Adams, Appleton, Hill et al., 2009) and also place increased economic strain on health care systems (ACSQHC, 2014). For these reasons, improving HL levels of the Australian population has been highlighted as a national priority (ACSQHC, 2014).

As health information and systems become increasingly difficult to navigate (ACSQHC, 2014), healthcare workers have been identified as a key source of health information and capacity building for health care consumers (henceforth termed 'clients' in this paper) and families (Johnson, 2014; Saunders, Palesy \& Lewis, 2018). More specifically, the Australian home care worker (HCW) has the potential to significantly impact the way older people and those with disabilities navigate the health care system and make decisions that positively impact on their health (Luz \& Hanson, 2015). Known by various terms such as home health aides, personal care attendants/aides/workers/assistants, direct care/support workers/assistants, carers/care assistants (ANF, 2009), HCWs currently account for more than three-quarters of the Australian home care workforce (Palesy et al., 2018). As an 
increasing number of older and disabled Australians are opting to remain in their own homes for care, the HCW workforce is rapidly expanding (Palesy et al., 2018; Productivity Commission, 2011). In Australia, HCWs are unlicensed and unregulated (ANF, 2009), tend to be lower skilled and are employed in place of nurses to perform a range of tasks for their clients such as personal care (e.g., bathing, toileting), domestic duties (e.g., shopping, housework) and community access (e.g., attending appointments, recreational activities) (ANF, 2009; Palesy et al., 2018). In view of their direct and frequent contact, clients consider HCWs as trusted professionals who are a reliable source of health-related information (Ifkovich, Lawson, Fraser \& Mason, 2013). However, there are concerns here. First, HCWs themselves may lack the HL skills which enable them to provide HL support to their clients, and secondly, there are concerns over how HCWs are currently trained and prepared to provide this kind of support.

The post-secondary school Certificate III in Aged Care or Home and Community Care are the most common qualifications for new entrants to the home care sector (Australian Skills Quality Authority [AQSA], 2013), designed to prepare HCWs to work safely with clients and provide client-centred care. However, formal qualifications are not mandatory for entry into home care work (ANF, 2009). In Australia, larger providers usually offer systematic training programs, while smaller home care agencies provide much less and/or ad hoc training, often citing financial constraints or a pre-existing skill set of their workers as reasons for this (Palesy \& Billett, 2017). Even when offered, formal training programs vary between training providers in terms of course content and delivery, are largely too short, and allow insufficient time in a workplace for sufficient skills development (ASQA, 2013; Lawn et al., 2016). Moreover, these programs may not develop the necessary expertise among HCWs to ensure adequate client HL (Naccarella, Osborne \& Brooks, 2016). Currently, a core HL curriculum checklist does not exist, even in the licensed health care professions such as 
nursing, medicine and pharmacy (Saunders et al., 2018). Reasons for this may include already overloaded health care curricula, a lack of guidance or research base to inform content (Saunders et al., 2018) or the time and economic constraints placed on home care organisations in relation to education and training (Palesy, 2017). Yet with the necessary skills and knowledge, there is great potential for HCWs, one of Australia's fastest growing workforces at the frontline of the home care sector, to positively impact on HL and health outcomes for their clients.
Aim
Building on earlier research (report pending) this study seeks to understand HCWs' experiences of providing HL support to their clients, and the type of education and training that might facilitate enhanced HL levels for both HCWs and their clients. The central premise is that while clients rely on HCWs for HL support, the type of support being provided is not clear, nor is whether HCWs feel comfortable and/or prepared to assist their clients to access, understand, appraise and apply information to make decisions and take action for their health and health care. This central premise informed three main categories of questioning to guide the study: (a) HCWs' HL experiences with clients; (b) HCWs' key HL needs and priorities; and (c) how HCWs should be trained to provide HL support. Data collected and analysed in relation to these three categories provides some insight into the types of HL support currently provided to Australian home care clients and proposes key recommendations for a training checklist to support improved HL levels of HCWs, ultimately improving outcomes for their clients. 


\section{Methodology:}

\section{Study design}

This mixed method study was underpinned by a constructionist approach. This paper presents Phase Two (of two) of the study, which used semi-structured, individual interviews with nine HCWs. Phase One (report pending) used a self-reported cross-sectional survey to collect data around HCWs' experiences in providing HL support to their clients, determine HCWs' HL education and training needs, and guide questioning in the interviews presented here. At the conclusion of this survey, respondents were asked if they would like to participate in a 30minute telephone interview to further explore their responses.

\section{Setting and participants}

Of the seventy-five HCWs who completed the survey in Phase One, nine HCWs agreed to be interviewed as part of Phase Two. They worked as either casual or permanent part-time HCWs for two separate home care service providers, performing a range of tasks for the frail aged and/or people with disabilities such as personal care (e.g., bathing, toileting), mobilising, domestic duties (e.g., housework, shopping) and community access (e.g., attending appointments, recreational and sporting activities). These nine HCWs comprised seven females and two males aged between 21 and 59 years, with most aged over 40 years (n $=6$ ). Seven of the interviewees were born in Australia and the remaining two were born in the United Kingdom, all had learned English as their first language. The highest level of education was a Bachelor Degree $(\mathrm{n}=2)$, two interviewees held school certificates, and five had completed a post-school Certificate or Diploma. One of the interviewees had worked in home care for over 30 years, while the others' experience ranged from nine months to ten years. Prior to their home care roles, they reported working in other areas such as hospitality, administration, childcare, hairdressing and building. In terms of gender, age, ethnicity and 
education level, the demographics reported here are representative of the Australian home care sector (Palesy et al., 2018).

\section{Procedure}

This study followed the principles outlined in the Declaration of Helsinki (2004). Ethical approval was obtained from the University's Human Research Ethics Committee (HREC ETH17-1114).

Support for the research and approval to recruit the HCWs was obtained from the managers of the two participating home care service providers. Flyers with information about both phases of the study, including information about informed consent, were distributed to all HCWs.

The primary researcher, an experienced nurse educator and researcher with home care experience, conducted all telephone interviews over a four-week period in 2017, at a time pre-arranged with each interviewee. Before the interviews commenced, the researcher reiterated the purpose of the study, informed the interviewees that participation was voluntary, that they could terminate the interview at any time and that the interview would be audiotaped and transcribed. Participants were also informed that their identities would be protected on all transcripts, reports and publications that resulted from the interviews. In addition to them having provided written consent to interview at the time of survey completion, verbal consent was then obtained to proceed. Each interview continued until the discussion around each question had waned and the interviewee had been afforded the opportunity to clarify any responses and provide any additional comments. Interviews lasted for an average 24 minutes in duration. 


\section{Instrument}

A semi-structured interview guide was developed for this research. Three main domains, guided by responses to the Phase One survey, informed questioning in the interview: (a) HCWs' experiences of providing HL support to their clients; (b) key HL training needs and priorities for HCWs; and (c) the type of training program that would best meet the HL needs and priorities of HCWs. These domains and sample questions from each are provided in Table 1.

\section{Insert Table 1 here.}

\section{Data analysis}

Transcribed interview data were imported into NVivo Pro 11 and analysed using a general inductive approach in accordance with five principles described by Thomas (2006). These principles are: (a) reading of the text data; (b) identifying specific segments of information related to answering research aims; (c) summarising these segments and arranging them in general categories; (d) editing the categories to reduce overlap and redundancy; and (e) creating a framework incorporating these categories (Thomas, 2006). With the three research aims firmly in focus, the primary researcher read and re-read the transcript many times, establishing a set of categories and subcategories (i.e., themes) that constituted the preliminary findings. To enhance the credibility of the findings, a second researcher independently analysed the data and developed a second set of categories and themes based on the research aim. Further analysis and discussion between the two researchers was done to establish the extent of overlap, reduce redundancy and develop a more robust set of categories and themes. The results were discussed regularly until consensus was reached. 


\section{Findings:}

Three overarching categories that emerged from the data were around: (a) the type of HL support provided to clients; (b) enablers and barriers to providing HL support; and (c) HL training needs. Although they were not pre-determined, the three categories were closely linked to the aims of the study (i.e., HCWs' HL experiences with clients; key HL training needs and priorities; how HCWs should be trained to provide HL support). Within each of the overarching categories, a number of sub-categories emerged. These categories and associated sub-categories, along with number of reporting sources and supporting quotes from interviewees are presented in Tables 2, 3, 4, 5 and 6. In relation to the category of HCWs' HL experiences with clients, one sub-category that emerged from the interview data was around the type of support that HCWs reported providing to their clients (Table 2). This included attending health-related appointments, providing health advice to clients, referring clients to external health professionals, researching and sourcing health-related information on the client's behalf, and advocating for their clients in the presence of health professionals.

\section{Insert Table 2 here.}

Also related to the overarching categories of HCWs' HL experiences with clients, and their key HL training needs and priorities, were a number of enablers and barriers that facilitated or prohibited HCWs from providing HL support. As enablers, a clear job description, support from the organisation (including a clear set of policies and procedures), being familiar with the client and their history and the HCW's own life and work experience were identified (Table 3). Conversely, some HCWs reported uncertainty about the scope of their home care roles, concerns about their own HL levels, and concerns about the limited amount of time 
they spent in each care episode with their clients. These were considered as barriers to effective HL support (Table 4).

\section{Insert Tables 3 and 4 here.}

From the pre-determined categories of key HL training needs and priorities, and how HCWs should be trained to provide HL support, two sub-categories around curriculum and pedagogies emerged from the interview data (Tables 5 and 6). HCWs identified a number of key training areas for their professional development, especially training in managing challenging behaviours, boundaries/scope of practice, and medication assistance. Face-toface delivery, opportunities for discussion and interaction, and client case studies were pedagogies highly favoured by HCWs.

\section{Insert Tables 5 and 6 here.}

\section{Discussion}

Findings suggest that HCWs in this study were providing HL support to their home-based clients. The types of support outlined in Table 2 are all consistent with Nutbeam's (2008) definition of HL, i.e., these workers were assisting their clients to access, understand, appraise and apply health information to manage their own health and health care. In some cases, rather than simply accessing health information, HCWs in this study were considered by their clients as the actual source of information i.e., 'experts' who could provide health advice. So, these workers were potentially going beyond Nutbeam's (2008) definition of HL. It seems that HCWs in this study actually wanted to provide HL support and advice, however they were concerned about working outside their role description and responsibilities. At times, some considered themselves to be ill equipped to provide this kind of support to their 
clients, often relying on their own life experience to provide assistance. These findings raise two concerns, firstly around whether the scope of the HCW role should include HL support (and to what extent) and secondly, how to ensure that HCWs are educationally prepared to ensure that they are providing accurate HL support.

The role of the Australian HCW is multi-faceted. For the most part HCWs are employed to provide personal hygiene assistance, domestic duties, social support and mobility assistance (Palesy et al, 2018), not to play an active role in enhancing clients' HL. This represents a missed opportunity, not only to improve health outcomes for clients but also for the HCWs themselves, their families and their communities (Lawn et al., 2016; Muramatsu, Yin \& Lin, 2017). In their pilot study, Muramatsu et al. (2017) educated HCWs on the implementation of a health promotion program "Healthy Moves for Ageing Well" (p3), aimed at improving physical activity of frail home-based older adults in the US. HCWs were taught how to run the program, assess, monitor and motivate their clients. Results showed improved health of both frail home-based clients (Muramatsu et al., 2017). Another US program implemented by Russell, Mola, Onorato, Johnson, Williams et al. (2017) educated HCWs on how to assist clients with chronic illnesses e.g., heart failure, to set health-related goals, gain knowledge, skills, tools and confidence in managing their own health. This program also reported improved quality of life for both HCWs and their clients (Russell et al., 2017). Such support is consistent with Nutbeam's (2008) definition of HL i.e., HCWs in these studies were assisting their clients to access, understand, appraise or apply health information to manage their own health and health care.

There is also the suggestion that the explicit inclusion of HL support in the scope of practice for HCWs provides more opportunities for career advancement in a role that is typically limited and characterised by high turnover and staff shortages (Luz \& Hanson, 2015; Palesy et al., 2018; Russell et al., 2017). In some way, HCWs are then acting as 
'community health workers' i.e., individuals with no formal medical education who coach individuals in managing their own health and assist with health care system navigation (Hartzler, Tuzzio, Hsu \& Wagner, 2018; Rosenthal, Brownstein, Rush, Hirsch, Willaert et al., 2010). Support such as this has proven to have such positive outcomes for clients as improved dietary behaviours and blood pressure control (Katigbak, Van Devanter, Islam \& Trinh-Shevrin, 2015), arthritis (Muramatsu et al., 2017) and diabetes (Rosenthal et al., 2010). Consequently, better scoping of the HCW role in terms of what they can and cannot do by way of HL support is needed. This research should include an exploration of whether or not HL support can be integrated into the existing HCW role (Muramatsu et al., 2017; Russell et al., 2017) or if it should be standalone 'community health worker' role (Rosenthal et al., 2010; Katigbak et al., 2015). In any case, making explicit the HL component of the $\mathrm{HCW}$ role in a workforce which is growing exponentially, stands to improve outcomes for clients, HCWs (e.g., career advancement and health outcomes) and their home care service providers (e.g., reduced staff turnover, improved workplace health and safety, financial imperatives) (Clarke, 2015; Lawn et al., 2016).

One strategy for improving HL outcomes for all stakeholders may be initiatives that embed HL across a range of HCW education and training areas. Findings in this study (Table 5) indicate that HL as a standalone training topic was not priority for HCWs. Instead, HCWs wanted training in many aspects of providing home-based care, such as managing challenging behaviours, boundaries and scope of practice, and assisting with medication. Indeed, HCWs report a strong commitment to training and up-skilling for their roles (King et al., 2013; Lawn et al., 2016). However, despite education and training being linked to better quality of care for clients (Clarke, 2015), improved emotional wellbeing of HCWs (Clarke, 2015), greater job satisfaction and workforce retention (Lawn et al., 2016) training is neither uniform nor mandated in the Australian home care sector (Palesy et al., 2018). As it stands, a 
core HL curriculum checklist for HCWs does not exist (Saunders et al., 2018). Two US home care providers have trialed very specific training programs for their HCWs aimed at enhancing HL e.g., within a physical exercise program (Muramatsu et al., 2017), and a health coach program for people with heart failure (Russell et al., 2017) with some success. However, given the financial restrictions of many Australian home care service providers and the subsequent ad-hoc approach to training (Palesy \& Billett, 2017), combined with a HCW workforce which is largely casualised and characterised by high staff turnover (Palesy et al., 2018), imposing HL training on top of what is already offered to HCWs is likely to be challenging. For these reasons, and in keeping with the HCWs' interview responses around curriculum and pedagogies, rather than delivering standalone HL training, some kind of training checklist that embeds HL enhancement strategies, that can be used by service providers when designing and delivering their existing in-house training might be worthy of consideration.

\section{A training checklist for improving HL support}

Study findings (Tables 5 and 6) identify a number of areas in which HCWs would like training, and suggest the pedagogies which might support this training. We used these findings, along with the broader literature on Australian HCWs (e.g., Palesy et al., 2018) to draft a checklist which could be applied to all kinds of HCW in-house training sessions for improving HL. Our checklist consists of eight key areas for consideration by home care organisations when designing and delivering their training. The eight key areas on the checklist are consultation with HCWs, consultation with clients, outlining boundaries and scope of practice, listing key organisational contacts, listing relevant services and networks, including client case studies and scenarios to illustrate various points, building in strategies to check understanding of the topic, and evaluating the effectiveness of the training. The 
intention is for this checklist to be applied to any training session, regardless of how much or how little training is offered by the organisation. For example, if an organisation offers only manual handling training to its HCWs, then the checklist could be applied. If an organisation offers a range of in-house topics e.g., manual handling, medications, infection control etc., then the eight key areas of the checklist could be considered when designing and delivering each session. The eight key areas are outlined and justified in Table 7.

\section{Insert Table 7 here.}

The eight key areas on the proposed training checklist (Table 7) incorporate the study's findings in relation to enablers, barriers, preferred pedagogies and curriculum for HCW HL training. Incorporating these areas into any existing in-house HCW training is aimed directly at improving HL and subsequent health outcomes for clients. However, there are additional advantages here. Training of this kind is also likely to increase HL of HCWs, so together with their clients, the current statistic of $60 \%$ of Australian adults that are considered to have acceptable HL may be increased. This is in line with Australia's national priority of addressing low HL levels (ACSQHC, 2014). Further, any training offered by a home care organisation, regardless of its content, duration or frequency, which is highly relevant to HCWs' work situations and encourages peer interaction and discussion (as per our training checklist) is more likely to be effectively transferred to the workplace (i.e., the client's home) (Palesy, 2017). Thereby, health outcomes for clients are likely to be improved, in addition to increasing job satisfaction and reducing staff turnover of HCWs (Palesy et al., 2018). The provision of clear boundaries from a home care organisation, along with supervisor support to apply HL training is also more likely to lead to improved outcomes for HCWs (e.g., job satisfaction), clients (e.g., better health outcomes) and organisations (e.g., reduced turnover 
and cost (Palesy, 2016). A pilot of this proposed training checklist with a number of home care organisations will be the focus of another study.

\section{Study limitations}

The nature of qualitative research and small sample $(n=9)$ creates limitations in the scale, scope and transferability of this study's findings (Sandelowski, 2000). Still, it is considered that the cohort and setting for this study represents a microcosm of the Australian home care sector. In view of the small sample, trialing and honing of data collection tools ensured that comprehensive data was collected from each participant (Blaikie, 2009). The findings here may also represent only one perspective, as the data were collected by a researcher with extensive home care experience. However, when combined with the research of others in different social positions and in different settings, they may contribute to a holistic picture of the issue (LeCompte \& Goetz, 1982). In essence, however, the findings of this unique and small-scale study should be viewed as tentative and exploratory.

\section{Conclusion}

Concerns have been reported about the inadequate health literacy levels of the general Australian adult population, and improving health literacy has been highlighted as a national priority. The increasing number of HCWs and their direct and frequent contact with clients suggests a readily accessible resource which has potential to improve HL outcomes for clients. Findings from this study indicate that HCWs are providing HL support to their homebased clients in the form of attending appointments, recommending referral to external health professionals and researching health information for clients, to name a few. A number of enablers and barriers to providing HL support were identified. It is still unknown whether the scope of the HCW role extends to HL support, or if they have sufficient knowledge and skills 
to provide competent assistance in this area. Therefore, further research is needed with larger cohorts and using different methodologies to measure the HL levels of both HCWs and clients, to further understand the types of HL support being requested of HCWs by their clients, to scope out the HCW role, and to understand how best to prepare HCWs to have a positive impact in this area. In the meantime, training which incorporates the eight key areas identified in this study (Table 7) may serve to enhance existing in-house training and bridge the HL gap. 
Table 1: Sample Questions from Interview Guide

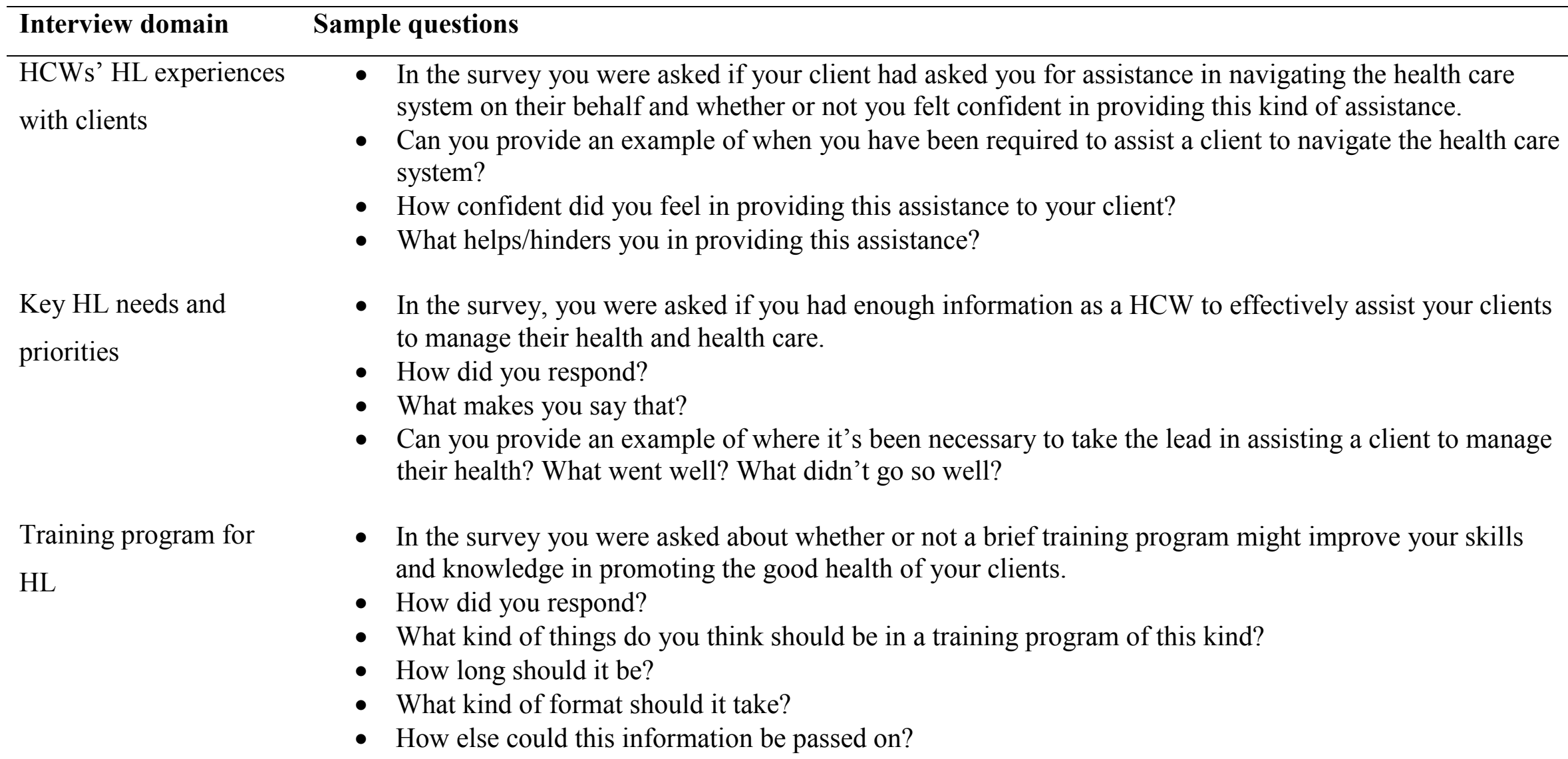


Table 2: HL Support Provided by HCWs

\begin{tabular}{|c|c|c|c|}
\hline Type of support & $\begin{array}{l}\text { Total no. of } \\
\text { sources } \\
\text { reporting }\end{array}$ & $\begin{array}{l}\text { Sub-themes/ no. of sources } \\
\text { reporting }\end{array}$ & Sample responses \\
\hline $\begin{array}{l}\text { Health-related } \\
\text { appointments with } \\
\text { clients }\end{array}$ & 7 & $\begin{array}{l}\text { Making appointments on behalf of } \\
\text { clients ( } 7 \text { ); attending the appointment } \\
\text { with the client (6); } \\
\text { reiterating/interpreting advice from } \\
\text { health professional (4); ensuring } \\
\text { follow up (4) }\end{array}$ & $\begin{array}{l}\text { "...having me there...I could listen to the doctor and hear what he was saying very much } \\
\text { helped because I could explain it later, what [the client] had forgotten." } \\
\text { "...I go to [the client's] medical appointments and I make his appointments." }\end{array}$ \\
\hline $\begin{array}{l}\text { Providing health } \\
\text { advice to clients }\end{array}$ & 5 & $\begin{array}{l}\text { General health advice (5); dietary } \\
\text { advice (4); medications (4); advice } \\
\text { about specific health conditions ( } 3 \text { ); } \\
\text { fitness (2); navigating health system } \\
\text { (2)wound care (1); sexual health (1); }\end{array}$ & $\begin{array}{l}\text { "[the client would] be eating something in particular and they'd want to know if it was } \\
\text { healthy, or what a good alternative would be." } \\
\text { So I...explained to [the client] the importance of taking [medication] to keep the } \\
\text { cholesterol at a level where it may help prevent heart attack...to give her the } \\
\text { confidence... to take it." }\end{array}$ \\
\hline $\begin{array}{l}\text { Referral of client to } \\
\text { external health care } \\
\text { professionals }\end{array}$ & 5 & $\begin{array}{l}\text { Referring to GP (5); other health } \\
\text { professionals (e.g., community nurse, } \\
\text { pharmacist) (5); ambulance services } \\
\text { (2) }\end{array}$ & $\begin{array}{l}\text { "[Clients have] talked to me and said is there something else I can take, and I've said you } \\
\text { have to go and see your doctor and then he'd refer you to what else to take." } \\
\text { "...in my role at the moment, I'd...get some support from a dietician, or [ask the client if } \\
\text { they], have a GP that [they] really respect, or... have a look on the internet and see what it } \\
\text { says..." }\end{array}$ \\
\hline $\begin{array}{l}\text { Researching health- } \\
\text { related information } \\
\text { on clients' behalf }\end{array}$ & 5 & $\begin{array}{l}\text { Medications information (4); } \\
\text { information around specific health } \\
\text { conditions (3); phoning an } \\
\text { organisation for information on } \\
\text { client's behalf (1) }\end{array}$ & $\begin{array}{l}\text { "I've had one client specifically ask me if I could do research on care facilities in the area, } \\
\text { what sort of ones there were." } \\
\text { "There was a Diabetes Foundation thing down in Victoria. So I rang them up and they } \\
\text { sent me all the info out and I had a big chat [to the client] about it..." }\end{array}$ \\
\hline Client advocacy & 2 & $\begin{array}{l}\text { Supporting self-management (2); } \\
\text { speaking up on behalf of client (2) }\end{array}$ & $\begin{array}{l}\text { "...we do go to doctor's appointments and stuff like that. We do go...if they need to go to } \\
\text { the chemist we go to the chemist with them...but we get them to actually ask...because } \\
\text { it's all about them...it's not about us." } \\
\text { "being in [hospitals] with [clients] and they're scared... and I'm dealing with the nurses } \\
\text { and trying to get the nurses and doctors to actually speak to the person rather than to me." }\end{array}$ \\
\hline
\end{tabular}


Table 3: Enablers for HCWs' Provision of HL Support

\begin{tabular}{|c|c|c|}
\hline Enabler & $\begin{array}{l}\text { No. of } \\
\text { Sources }\end{array}$ & Sample Responses \\
\hline $\begin{array}{l}\text { Being clear about job description } \\
\text { and scope of practice }\end{array}$ & 7 & $\begin{array}{l}\text { "I know that I could get into trouble and I don't want my clients to follow advice that's not qualified, } \\
\text { you're not qualified for that". } \\
\text { "...in terms of professional and personal boundaries...I'm...there for a specific role, and crossing } \\
\text { that line isn't always good...it's a hard balance..." }\end{array}$ \\
\hline Organisational support & 6 & $\begin{array}{l}\text { "...if you don't know you have to refer it on to someone...the key worker or management." } \\
\text { "I know I can get on the phone and speak to the coordinator and just run it by them. It wouldn't be a } \\
\text { problem. You're never really alone." }\end{array}$ \\
\hline $\begin{array}{l}\text { Having a comprehensive } \\
\text { background/history of the client }\end{array}$ & 5 & $\begin{array}{l}\text { "... when it comes to...personal care, it would be good to have more of an understanding of [the } \\
\text { client's health history]." } \\
\text { "...I think you need to have an awareness of what their weaknesses are when it comes to their health } \\
\text { so that you can be aware of that when you're with them in case something goes wrong." }\end{array}$ \\
\hline Previous work/life experience & 5 & $\begin{array}{l}\text { "...I haven't always been very happy with my diet and with experience...I feel like if I give them } \\
\text { this [advice] it is not going to be damaging." } \\
\text { "...I...am constantly explaining to [the client] every day why he's taking it [medication] and he will } \\
\text { ask what are the effects of thyroid and I will explain that to him, and the only reason I can do that is } \\
\text { because I have thyroid." }\end{array}$ \\
\hline Clear policies and procedures & 4 & $\begin{array}{l}\text { "Just follow procedure. Company policy, just follow that. You know. They don't really want me to } \\
\text { go on about what medication is to these clients, just here it is. Follow procedure, it's the safe way } \\
\text { really just follow policy. So, I don't try and breach that ever really cos you just steer yourself into a } \\
\text { rocky road really." }\end{array}$ \\
\hline & & $\begin{array}{l}\text { "I've got an approach, it keeps you safe really. I'm very firm on being - if you stick to policy, you } \\
\text { can keep yourself safe really. You know they're there as much to protect you as well." }\end{array}$ \\
\hline
\end{tabular}


Table 4: Barriers for HCWs' Provision of HL Support

\begin{tabular}{|c|c|c|}
\hline Barrier & $\begin{array}{l}\text { No. of } \\
\text { Sources }\end{array}$ & Sample Responses \\
\hline \multirow{2}{*}{$\begin{array}{l}\text { Uncertainty about job } \\
\text { description and scope of } \\
\text { practice }\end{array}$} & 3 & $\begin{array}{l}\text { "I don't know if it's really in my job description to contact healthcare providers on behalf of } \\
\text { [my client]..." }\end{array}$ \\
\hline & & $\begin{array}{l}\text { "...we do have all of the - you know, the roles and responsibilities when you get to work } \\
\text { and everything, but we are so heavily involved in their lives, and often we're getting more } \\
\text { insight into their lives than the nurse, or the chemist, or the doctor. But then we're still not } \\
\text { able to provide that medical advice, because of the restrictions of our role... and we don't } \\
\text { often know, ourselves, to provide to the client, and whether we can provide that } \\
\text { information." }\end{array}$ \\
\hline \multirow[t]{2}{*}{ HCWs' low HL levels } & 3 & $\begin{array}{l}\text { "[I] had a client and I had felt a bit...like I was out of my depth and I didn't know what to } \\
\text { do, so I think that...it's probably not really in my ballgame." }\end{array}$ \\
\hline & & $\begin{array}{l}\text { "...I don't have much experience myself...I don't always go to the doctor's, go to the } \\
\text { hospital...I'm not always around those environments." }\end{array}$ \\
\hline \multirow[t]{2}{*}{ Limited time with client } & 3 & $\begin{array}{l}\text { "I'm still learning and getting to know people. So it's hard to know, and I'm only seeing } \\
\text { them once a week if that...I think that makes me feel a little less confident about knowing } \\
\text { how to say things." }\end{array}$ \\
\hline & & $\begin{array}{l}\text { "...You're not going to the doctor appointments every time. I think if I was more involved, I } \\
\text { would definitely feel that I had a place to make a suggestion or to be more informed, but } \\
\text { often you're not always that involved with them." }\end{array}$ \\
\hline
\end{tabular}


Table 5: HCWs' Training Curriculum Needs

\begin{tabular}{|c|c|c|}
\hline Curriculum & $\begin{array}{l}\text { Number of } \\
\text { Sources Reporting }\end{array}$ & Sample Responses \\
\hline Managing challenging behaviours & 6 & $\begin{array}{l}\text { "...how to...handle people with different behaviours or how to speak to people...how touch } \\
\text { helps and the tone of your voice and body language and all of that sort of thing..." } \\
\text { "...my main interest at the moment lies in the area of dementia, the behaviours, how to deal } \\
\text { with different behaviours with people..." }\end{array}$ \\
\hline Boundaries and scope of practice & 4 & $\begin{array}{l}\text { "...it would be good to have a bit more of a clear understanding of... what advice we can and } \\
\text { can't provide." } \\
\text { "...it often does get blurred where you sit amongst the doctor, the chemist, the hospital, the } \\
\text { nurse. Because we are fully involved, but we're a little bit blurred, so...maybe getting a more } \\
\text { clear understanding of where we can and can't provide advice..." }\end{array}$ \\
\hline Medications & 3 & $\begin{array}{l}\text { "I feel I don't have enough information... It's all changing constantly...there's also a lot of stuff } \\
\text { we don't have enough information on, so fully understanding all the medication stuff." } \\
\text { "I must admit when I first started the job the medications stuff was a nightmare.. very scary. } \\
\text { Being relied on by someone for their medication potentially could kill them, you know." }\end{array}$ \\
\hline Sexual health & 2 & \multirow{3}{*}{$\begin{array}{l}\text { "... sexual health and stuff like that...if I'm looking at a person holistically, and that's part of } \\
\text { their world, I mean, as a [HCW]... would I feel qualified to talk to someone about their sexual } \\
\text { health?" }\end{array}$} \\
\hline Health system navigation & 2 & \\
\hline Orientation to the $\mathrm{HCW}$ role & 2 & \\
\hline Wound care & 1 & \multirow{2}{*}{$\begin{array}{l}\text { "I sort of wanted to know... what clients can access through different medical places, or what } \\
\text { their - funding, or programs, if there's things out there for them that we can suggest." }\end{array}$} \\
\hline Health promotion & 1 & \\
\hline Medical terminology & 1 & \multirow{3}{*}{$\begin{array}{l}\text { "I wish I knew some better techniques to help, really help [clients] understand the } \\
\text { consequences, and maybe support them in making healthy lifestyle choices..." }\end{array}$} \\
\hline First aid & 1 & \\
\hline Ageing process & 1 & \\
\hline
\end{tabular}


Table 6: HCWs' Training Pedagogical Needs

\begin{tabular}{|c|c|c|}
\hline Pedagogies & $\begin{array}{l}\text { Number of } \\
\text { Sources Reporting }\end{array}$ & Sample Responses \\
\hline Face-to-face & 5 & $\begin{array}{l}\text { "You can see that you are not alone and what you're experiencing is what everyone else is } \\
\text { experiencing." } \\
\text { "I think I'd be better with face to face training because you can ask questions there and then." }\end{array}$ \\
\hline Discussion and interaction & 5 & $\begin{array}{l}\text { "...some [HCWs] will come up with an example and you can relate to it...I can imagine that } \\
\text { sometimes people might be out there thinking... if anyone else has experienced this." } \\
\text { "I get a lot more out of the interactive sessions. Or I feel like I need to learn more. I need to } \\
\text { take it more seriously when there's a bit of accountability than if...I can just do it in my own } \\
\text { time and there's not going to be any feedback..." }\end{array}$ \\
\hline $\begin{array}{l}\text { Incorporating real client scenarios } \\
\text { or case studies }\end{array}$ & 4 & $\begin{array}{l}\text { "I know I learn well when I've got something to apply it to." } \\
\text { "... as long as there's no names and stuff like that - confidentiality...but if you're relating } \\
\text { something that's actually happened..." }\end{array}$ \\
\hline $\begin{array}{l}\text { Group work } \\
\text { Self-paced learning }\end{array}$ & & $\begin{array}{l}\text { [It's good if we]... all get into little groups... and have like focus groups as well...even if we } \\
\text { get together in a big group settings and then split off into different groups" }\end{array}$ \\
\hline Online programs & 2 & "Also, maybe like putting things in practice, so after the group training going away and \\
\hline $\begin{array}{l}\text { Opportunities to practice } \\
\text { Regular training and }\end{array}$ & 2 & $\begin{array}{l}\text { putting things, and then coming back and meeting again, and seeing how these things have } \\
\text { been successful or not successful." }\end{array}$ \\
\hline One-off orientation training & 1 & $\begin{array}{l}\text { "...they give us the booklets to take home with all that information... and quite often some } \\
\text { exercises and questions and things at the back to do. I'm happy to do that sort of stuff. I'm not } \\
\text { big on where you've got to be up and interactive, play role and all that sort of thing." }\end{array}$ \\
\hline
\end{tabular}


Table 7: Proposed Training Checklist for Improving HCWs' HL Levels

Key area
Consultation with HCWs in training design

Consultation with clients

Outline HCWs' personal boundaries and scope of practice in relation to the training topic

List key organisational contacts relevant to the training topic

List available services and networks relevant to the training topic

Including relevant scenarios and group work

Build in strategies to check understanding of the topic

Evaluate of effectiveness of the training.

\section{Rationale and Intended Outcomes}

Ascertain types of challenges commonly encountered; ensure that training meets their HL and other training needs; increased job satisfaction by giving HCWs some ownership of training; may lead to reduced staff turnover and organisational costs

Gain an idea of type of support issues experienced; ensure that training meets their HL and other service needs (i.e., client-centred care); increased satisfaction by giving clients ownership of their support; improved health outcomes for clients

HCWs will have a clear understanding of what they can and cannot provide in terms of HL support, health advice, and the training topic; increased job satisfaction; positive health outcomes for clients if HCWs know when to refer

Provide organisational support for HCWs; improved communication with organisation likely to lead to increased job satisfaction; better health outcomes for clients

Improved HL for both HCWs and their clients as they will understand the most appropriate places to access health information; better health outcomes for both

Ensure relevance to work setting; build on existing knowledge; incorporate preferred pedagogical approach as per study findings; allow networking; improved HL

Improved HL for HCWs and their clients; better health outcomes for both

Check understanding of information; continuous improvement of curriculum and pedagogies; improved HL for HCWs and their clients; better health outcomes for both 


\section{References}

Adams RJ, Appleton SL, Hill CL, et al. (2009). Risks associated with low functional health literacy in an Australian population. Med J Aust, 191, 530-534.

Australian Commission on Safety and Quality in Health Care (2014). Health literacy: Taking action to improve safety and quality. Sydney: ACSQHC.

Berkman ND, Sheridan SL, Donahue KE, Halpern DJ, Crotty K. (2011). Low health literacy and health outcomes: an updated systematic review. Ann Intern Med, 155,(2), 97-107.

Clarke, M. (2015). To what extent a 'bad' job? Employee perceptions of job quality in community aged care. Employee Relations, 37(2), 192-208. doi:10.1108/ER-11-20130169

Hartzler, A. L., Tuzzio, L., Hsu, C., \& Wagner, E. H. (2018). Roles and functions of community health workers in primary care. The Annals of Family Medicine, 16(3), 240-245.

Johnson A. (2014). Health literacy, does it make a difference? Australian Journal of Advanced Nursing. 31(3)39.

Katigbak, C., Van Devanter, N., Islam, N., \& Trinh-Shevrin, C. (2015). Partners in health: A conceptual checklist for the role of community health workers in facilitating patients' adoption of healthy behaviors. American journal of public health, 105(5), 872-880.

King, D., Mavomaras, K, Wei, Z., He, B, Healy, J, Macaitis, K, Moskos, M \& Smith, L. (2013). The Aged Care Workforce, 2012. Canberra: Australian Government Department of Health and Ageing; 2012

Lawn, S., Westwood, T., Jordans, S., Zabeen, S., \& O’Connor, J. (2016). Support workers can develop the skills to work with complexity in communicated aged care: an Australian study of training provided across aged care community services. Gerontology \& Geriatrics Education. doi:10.1080/02701960.2015.1116070

Luz, C., \& Hanson, K. (2015). Filling the care gap: personal home care worker training improves job skills, status, and satisfaction. Home Health Care Management \& Practice, 27(4), 230-237.

Muramatsu, N., Yin, L., \& Lin, T. T. (2017). Building Health Promotion into the Job of Home Care Aides: Transformation of the Workplace Health Environment. International journal of environmental research and public health, 14(4), 384.

Nutbeam, D. (2008). The evolving concept of health literacy. Soc Sci Med, 67(12), 20722078.

Palesy, D. (2017). Brief classroom training sessions for workplace readiness: are they effective?. International Journal of training research, 15(2), 119-135.

Palesy, D. (2016) Home Health Aide Training: An Appeal for Organizational Support, Home healthcare now, vol. 34, no. 7, pp. 381-387

Palesy, D., \& Billett, S. (2017). Learning manual handling without direct supervision or support: a case study of home care workers. Social Work Education, 36(3), 273-288.

Palesy, D., Jakimowicz, S., Saunders, C., \& Lewis, J. (2018). Australian home care work: an integrative review. Home health care services quarterly.

Rosenthal, E. L., Brownstein, J. N., Rush, C. H., Hirsch, G. R., Willaert, A. M., Scott, J. R., ... \& Fox, D. J. (2010). Community health workers: part of the solution. Health Affairs, 29(7), 1338-1342.

Russell, D., Mola, A., Onorato, N., Johnson, S., Williams, J., Andaya, M., \& Flannery, M. (2017). Preparing home health aides to serve as health coaches for home care patients with chronic illness: Findings and lessons learned from a mixed-method evaluation of two pilot programs. Home Health Care Management \& Practice, 29(3), 191-198. 
Sandelowski, M. (2000). Focus on research methods-whatever happened to qualitative description? Research in nursing and health, 23(4), 334-340.

Saunders, C., Palesy, D., \& Lewis, J. (2018). Systematic review and conceptual checklist for health literacy training in health professions education. Health Professions Education.

Thomas, D. (2006). A general inductive approach for analysing qualitative evaluation data. American Journal of Evaluation, 27(3), 237-246. 